\begin{tabular}{|c|l|}
\hline Title & Geothermal heat flux into deep cal dera lakes Shikotsu, Kuttara, Tazawa and Towada \\
\hline Author(s) & Boehrer, Bertram; Fukuy ama, Ryuji; Chikita, Kazuhisa A. \\
\hline Citation & $\begin{array}{l}\text { Limnology, 14(2), 129_134 } \\
\text { https://doi.org/_0.1007/310201-013_0399-7 }\end{array}$ \\
\hline Issue Date & 2013_04 \\
\hline Doc URL & http://hdl.handle.net/2115/54968 \\
\hline Rights & The original publication is available at link.springerlink.com. \\
\hline Type & article (author version) \\
\hline File Information & geotherm20120806_BB.pdf \\
\hline
\end{tabular}

Instructions for use 


\title{
Geothermal heat flux into deep caldera lakes Shikotsu, Kuttara, Tazawa and
}

\section{Towada}

\section{Bertram Boehrer ${ }^{1}$, Ryuji Fukuyama ${ }^{2}$, Kazuhisa Chikita $^{3}$}

\author{
${ }^{1}$ UFZ-Umweltforschungszentrum Leipzig-Halle GmbH, Magdeburg, Germany \\ Bertram.Boehrer@ufz.de \\ Brueckstrasse 3a \\ D-39114 Magdeburg \\ Germany \\ Phone: ++49 3918109441 \\ Fax: ++49 3918109150 \\ ${ }^{2}$ Hokkaido Institute of Environmental Sciences. W12, N19, Kitaku, Sapporo, Hokkaido, \\ JAPAN, Phone:81-11-747-3563 \\ ${ }^{3}$ Laboratory of Physical Hydrology, Faculty of Science, Hokkaido University, Sapporo, 060- \\ 0810, JAPAN, phone: +81-11-706-2764
}

key words:

physical limnology, heat flux, stratification, density, deep water

running header: geothermal heat flux into deep caldera lakes

for submission to "Limnology" 


\begin{abstract}
Geothermal heat fluxes into the deepest waters of four caldera lakes were measured. Temperature profiles within the stratification period between July and November 2007 5 allowed a quantification of the acquired heat. Due to their enormous depth, heat input from the lake bed was locally separated from heat fluxes at the surface. In conclusion, a direct measurement of geothermal heat input could be accomplished. Although enhanced geothermal activity could be suspected in all cases, two lakes showed a geothermal heat flux of 0.29 or $0.27 \mathrm{~W} / \mathrm{m}^{2}$ (Lake Shikotsu and Lake Tazawa), as found in other regions not affected by volcanism, while both other lakes (Lake Kuttara and Lake Towada) showed a much enhanced heat input of 1 or $18.6 \mathrm{~W} / \mathrm{m}^{2}$, respectively. In conclusion within our investigated set, all lakes acquired more heat from the underground than the continental heat flux average. Hence, the heat flux into the lakes from the ground was not dominated by the temperature gradient implied by the inner heat of the Earth. Other effects like the general temperature difference of deep lake water and the groundwater or local sources of heat in the underground deliver more important contributions. Obviously the flow of water in the underground can play a decisive role in the heat transport into the deep waters of lakes.
\end{abstract}




\section{Introduction}

Lake stratification and wind circulation are driven by forcing from outside, such as heat fluxes and wind stress. Most of the fluxes happen at the lake surface by exchange with the atmosphere, such as gas exchange, evaporation and precipitation and heat input and loss by irradiation or sensitive heat flux, to just mention the few leading processes. Deep recirculation in winter is pivoted very sensitively at a balance of remaining density stratification and input of kinetic energy. Also the smaller contributions of heat exchange from the ground must be considered. As this heat enters the lake at its base, the deepest layers experience a destabilisation in terms of density gradient, and hence full overturns are supported and redistribution of solutes and oxygen over the entire water body is accomplished.

The global average for geothermal heat flux amounts to $0.065 \mathrm{~W} / \mathrm{m}^{2}$ below continents (Pollack et al. 1993) and may serve as a first estimate for the heat flux into lakes. However, local variability is high on the global scale. Most measurements lie in the range between 0.04 and $0.1 \mathrm{~W} / \mathrm{m}^{2}$, higher values are rare and may reach $0.25 \mathrm{~W} / \mathrm{m}^{2}$. No measurements beyond 1 $\mathrm{W} / \mathrm{m}^{2}$ are reported in Pollack et al. (1993). If we consider heat input into lakes, we look at a slightly different mechanism. Deep water in lakes of the temperate climate zone is formed in the cold period of the year, and represents a cold location in the environment. Hence it would not be too surprising, if lakes would acquire more heat than just the geothermal heat flux. Hence the heat flux of $0.101 \mathrm{~W} / \mathrm{m}^{2}$ (Pollack et al. 1993) into the deep ocean may also be considered for comparison. Contrary to the ocean, deep lakes in a temperate climate represent cold spots well confined in a warmer environment. Hence, they may attract more heat.

Indeed, lakes located where no volcanic activity was present were reported to be exposed to heat fluxes from the ground in the range of $0.23 \mathrm{~W} / \mathrm{m}^{2}$, e.g. von Rohden and Ilmberger (2001). They found this value when they derived vertical transport coefficients by implementing gradient flux calculations to a $\mathrm{SF}_{6}$ tracer experiment in the Lakes Wallendorfer See (max. depth 30m) and Rassnitzer See (max. depth 38m) in the abandoned lignite mine Merseburg-Ost in Central German mining district (see e.g. Böhrer et al. 1998) located in an unconsolidated rock environment. In shallow areas of Mining Lake 111 (max. depth $10 \mathrm{~m}$ ) in the Lusatian mining district of Germany, Karakas et al. (2003) showed that the heat balance might be also negative in the beginning summer stratification, as sediments had cooled while 
they were exposed to cold water temperatures during winter. The results were concluded from gradient flux calculations by requiring reasonable values for the vertical transport coefficients.

Finally Crawford and Collier (1997, 2007) presented heat fluxes into the deep water body of Crater Lake (max. depth 594 m) in Oregon, U.S.A., in a very similar system compared to presented lakes. Though they presented differences of stored heat between years, i.e. they also included the heat transfer into and from the upper water body, their time series of heat fluxes could be used for an estimate of heat flux from the ground in years with few deep water renewal, i.e. hardly any heat exchange with the shallower water layers. Their 14 years time series reached maxima of around $1 \mathrm{~W} / \mathrm{m}^{2}$. From the monimolimnion of the tropical meromictic Lake Kivu (max. depth 485 m) in East Africa, Schmid et al. (2010) reported heat gain in the range of 0.05 to $0.2 \mathrm{~W} / \mathrm{m}^{2}$, to which the (double) diffusive heat loss to shallower layers of 0.016 to $0.18 \mathrm{~W} / \mathrm{m}^{2}$ had to be added to find the amount of heat delivered from the ground.

In this contribution, we investigated the case of very deep lakes, which are of general public interest to Japan (e.g. Abukawa et al. 2012, see also Global Volcanism Program www.volcano.si.edu for general information on the investigated volcanic areas). Other than in the cases above, we concentrated here on providing a direct measurement of geothermal heat flux into lakes. The depth of very deep caldera lakes was sufficient that heat introduced over summer from the surface remained locally separated from the heat from the ground. Hence, heat input from the ground into the lakes could be measured much more accurately than in the estimates above. The constant lake water temperatures at great depth (e.g. Yoshimura 1936 a, b) also indicate pretty constant heat fluxes over the annual cycle; i.e. beyond the observation period. The details of the heat transmission - such as the role of groundwater flow - are not distinguished in this approach. All selected lakes are caldera lakes, some with known geothermal activity close to the lake basins. Hence direct measurements of heat fluxes in such areas could be of interest per se. We selected a time period between July and November 2007 covered by the summer stratification when large scale exchanges in the vertical could be excluded. 


\section{Lakes and Measurements}

We selected four very deep caldera lakes in Japan, namely lakes Shikotsu, Kuttara, Tazawa and Towada. For some more information on the geological surrounding of the caldera lakes, see the work by Yamagata (1993) for lakes Shikotsu and Kuttara, by Kano et al. (2007) for Lake Tazawa or by Kudo (2010) for Lake Towada, respectively. The lakes were located in southern Hokkaido or in the mountainous Tohoku area (Northern Honshu, see Fig. 1). Maximum depths ranged from $148 \mathrm{~m}$ to $423 \mathrm{~m}$. All lakes consisted of a single round basin with steep side walls. All lakes experienced cold winters and hence formed deep water temperatures close to $4^{\circ} \mathrm{C}$ (see e.g. Boehrer et al. 2009). Deep water temperatures varied only marginally in the range of fractions of a degree over the annual cycle. For more information on the circulation of the lakes see Boehrer et al. (2008, 2009).

Lake Shikotsu (as well as Lake Kuttara) showed a thermobaric stratification: i.e. pressure affected the temperature of maximum density with consequences for the deep recirculation during winters. Lake Shikotsu could be considered a beautiful representation and demonstration model of a horizontally homogeneous, thermobarically stratified lake (Boehrer et al. 2008, 2012).

We used an Ocean Seven 316 multiparameter probe (Idronaut, Italy). The probe carried sensors for pressure (range 0 to $1000 \mathrm{dbar}$ ), temperature (range $0^{\circ} \mathrm{C}$ to $30^{\circ} \mathrm{C}$ ), electrical conductivity (freshwater range: 0 to $6 \mathrm{mS} / \mathrm{cm}$ ), dissolved oxygen, $\mathrm{pH}$ and other quantities not required for this investigation. For back-up and data confirmation, a CTD probe (Sea \& Sun Technology, Germany) was attached to the multiparameter probe and operated independently (see Boehrer et al. 2009). Probes were run in continuous data collection mode: Ocean Seven at $1.2 \mathrm{~Hz}$, and CTD at $4 \mathrm{~Hz}$.

Both manufacturers claimed an accuracy of about $0.005 \mathrm{~K}$ for temperature and 0.005 $\mathrm{mS} / \mathrm{cm}$ for conductivity. The results however showed a difference of $0.025 \mathrm{~K}$ between probes. Measured conductivities agreed within 0.0025 mS/cm between probes. However, calculation of heat input is based on the measurement of small temperature differences between July and November measurements. The measured profiles showed identical temperatures at mid depth, which confirmed that no noticeable drift of calibration had taken place. In the cases of Lake Shikotsu, Lake Kuttara, Lake Towada the measured temperature difference could be 
confirmed within $10 \%$ by data of the CTM probe, only in the case of Lake Tazawa, the relative difference turned out to $20 \%$, because of the minuscule temperature changes over the observation time.

Before profiling, oxygen and pressure sensors were calibrated on site. The probes were lowered at speeds of about $0.3 \mathrm{~m} / \mathrm{s}$ by hand on a rope. Even at depths beyond $400 \mathrm{~m}$, ground contact could be felt by releasing tension in the rope. The probes were immediately pulled back up, and contact with lake beds could be verified with several measurements at constant depth in data files after data recovery.

\section{Results:}

The presentation of the results starts from the Northern end.

\subsection{Lake Shikotsu}

According to its reputation as a thermobarically stratified lake, Lake Shikotsu showed temperatures below $4^{\circ} \mathrm{C}$ also during summer stratification (Fig.2 upper row). The conductivity profiles showed (very) small gradients of dissolved substances. The distinct tiny step, which was observed in spring profiles of 2005 (Boehrer et al. 2008, 2009) and which clearly defined the circulation depth, was not visible in summer or autumn 2007. Possibly the later time of the year had allowed for some mixing and a previous step would have smoothed out.

A close look at conductivity reveals a slight increase in the deep water towards the lake bed in the July profile and even more in the November profile (Fig. 2, upper row, last column). Obviously, some dissolution from the sediment had increased the conductivity. This small increase contributed to density and hence created a stable stratification in the bottom layer. Supposing the additional conductivity originated from decomposed material, this would contribute heat to the deep water. A quantitative estimate of the amount of produced carbon dioxide (and bicarbonate) showed that reaction enthalpy and dissolution would contribute far less than $1 \mathrm{mK}$ to the temperature of water. Following the estimates of "Energy Fluxes in the 
Bottom Boundary Layer” of Imboden and Wüest (1995), we found an estimate of the order of $1 \mathrm{mK}$ from bottom friction, if all energy was deposited in the bottom $1 \mathrm{~m}$. Temperature increase in the bottom boundary was much larger $(\sim 20 \mathrm{mK})$ over a layer of more than $100 \mathrm{~m}$ thickness, and hence could not be a consequence of decomposing organic material nor of mechanical work.

The area between both profiles represented the heat input between the measuring dates:

$$
H=\int\left(T_{\text {Nov }}-T_{J u l}\right) \cdot \rho c_{p} d z
$$

Now due to the enormous depth of Lake Shikotsu and the increased density by released substances, the heated layer at the bottom of the lake stayed locally clearly separated from heat exchange at the surface. Hence the integral spanned over the depth range which represents the layer heated from below. There was no reason to suspect any heat transport from the surface to the bottom over the stratified period July to November 2007. Hence we interpreted the resulting heat flux of dividing $H$ by the enclosed time interval as geothermal heat flux into a lake.

$$
h=H / \Delta t=0.29 \mathrm{~W} / \mathrm{m}^{2}
$$

Both paths of inflowing groundwater and sensible heat flux were included in this approach. As a consequence, we also disregarded any geothermal heat input above the layer covered by the integral. The resulting value lay considerably higher than average heat flux from the inner Earth through continents $\left(0.065 \mathrm{~W} / \mathrm{m}^{2}\right)$ and into oceans $\left(0.101 \mathrm{~W} / \mathrm{m}^{2}\right.$, Pollack et al., 1993).

\subsection{Lake Kuttara}

The approach for Lake Kuttara was the same as for Lake Shikotsu. Also in this case, the heated bottom layer was clearly separated from the heat exchange at the surface (Fig.2 second row). The numerical evaluation however revealed a higher value of $1.0 \mathrm{~W} / \mathrm{m}^{2}$ for the heat flux from the lake bed.

The profiles of temperature and conductance revealed two steps in both profiles of July and November. Temperature affected density stratification in an unstable way, while this effect was balanced by the density effect of dissolved substances. Hence the preconditions for double diffusive convection and hence the formation of staircases were given (e.g. Boehrer 2012). Double diffusive convection forming staircases had been known for tropical lakes 
(Newman 1975, e.g. Schmid et al. 2004), but had also been observed in lakes of the temperate climate zone (e.g. von Rohden et al 2010). Layer thicknesses usually lie in the range of decimetres to one meter.

Calculating the density difference due to temperature differences $(0.2 \mathrm{~K}$, thermal expansion coefficient $\alpha \approx 2 \cdot 10^{-6} / K$ from Boehrer et al. 2012) between 90 and $140 \mathrm{~m}$ depth and doing the same for the conductivity differences $\left(1 \mu \mathrm{S} / \mathrm{cm}, \beta=0.6 \mathrm{~kg} / \mathrm{m}^{3} /(\mathrm{mS} / \mathrm{cm})\right.$ e.g. Bäuerle et al. 2001 referred to $25^{\circ} \mathrm{C}$ as reference) yielded a density ratio of

$$
R_{\rho(\text { diffusive })}=\frac{\beta \Delta S / \Delta z}{\alpha \Delta T / \Delta z}=6
$$

for diffusive regime conditions. This value implied overall stable conditions, as density gain due to solutes overcame the destabilization due to temperature gradient. A value below 10 indicated the possibility for double diffusive convection. The scaling of Kelley (1984) delivered a value in the range of $8 \mathrm{~m}$ for the layer thicknesses of possibly resulting staircases, which at least met the order of magnitude of observed 25 m layers. In conclusion, chances were good that the steps originated from double diffusion convection, though they were extraordinary high.

\subsection{Lake Tazawa}

For Lake Tazawa, the approach was the same: although the stratifying contribution of released substances from sediments was too small to be resolved and too small to confine the heat to a defined layer close to the bottom (Fig. 2 third row). Hence the heat must have driven convection and heat was forwarded to an altitude where it touched the temperature stratification formed from the surface. Hence the calculation could still be done in the same way as for Lake Shikotsu. We found a value of $0.27 \mathrm{~W} / \mathrm{m}^{2}$ close to the value in Lake Shikotsu and no verification of additionally increased heat input due to volcanic geology.

\subsection{Lake Towada}

Lake Towada showed increasing temperatures throughout the entire profiles (Fig. 2 bottom row; excluding a thin surface layer). Hence the separation of heat input at depths and 
from the surface cannot be done as simply as in the previous lakes. At $90 \mathrm{~m}$ depth, however, both July profile and November profile showed a temperature minimum. Net transport of heat across this line should vanish on both dates and probably most of the time between. Though arguable, we took the $90 \mathrm{~m}$ mark as the upper end of our integral.

The calculation revealed $18.6 \mathrm{~W} / \mathrm{m}^{2}$, which was more than two orders of magnitude larger than the global average of geothermal heat flux and much more than in the other lakes of this study. It was suspected that submerged springs carry the heat into the deep water of Lake Towada. A maximum in the conductance profile at 200m depth supported this idea. Possibly also a short circuit of lake water could accomplish a heat transport: Lake water could enter the ground and acquire heat from geothermal sources. The increased buoyancy could allow the water to re-enter the lake. Nishimura et al. (1999) had already attempted clarifying the origin of the deep waters in Lake Towada. 


\section{Conclusions}

All investigated lakes showed heat fluxes into the deep water body from the ground: From high accuracy and high resolution profiles of temperature and electrical conductivity, the heat flux over the stratified period from July to November 2007 could be quantified. In all investigated lakes, geothermal heat fluxes (Lake Shikotsu $0.29 \mathrm{~W} / \mathrm{m}^{2}$, Lake Tazawa 0.27 $\mathrm{W} / \mathrm{m}^{2}$ ) overcame the global average of heat flux from the inner Earth of about $0.065 \mathrm{~W} / \mathrm{m}^{2}$ through continents and even the value of $0.1 \mathrm{~W} / \mathrm{m}^{2}$ into oceans. The heat flux into lakes could however be even much larger, e.g. Lake Kuttara $1 \mathrm{~W} / \mathrm{m}^{2}$ or Lake Towada $18.6 \mathrm{~W} / \mathrm{m}^{2}$.

All investigated lakes were caldera lakes, and they all lie in still volcanically active zones. Higher temperatures in the ground than the global average could be suspected. In Japan in general, precipitation overcomes evaporation from a water surface. Lakes produce an outflow either at the surface or through the ground. Groundwater outflow had been documented in the case of Lake Kuttara (Chikita el al. 1995) and also Lake Ikeda (Terada 1996, Hirae et al. 1997, Momii 2003), which lies in Kyushu but was not part of this investigation. Outflowing groundwater might well receive considerable heat from the ground, as e.g. demonstrated by the appearance of hot springs at the bottom of Lake Kuttara, possibly connected to thermal springs in Gigokudani “Hell’s Valley” of Noboribetsu (Chikita et al. 1995). This heat however is felt in the lake only, if the heated groundwater can find its way into the lake, as it is suspected for deep areas in Lake Towada (see also Nishimura et al., 1999).

In all presented lakes, the input of heat from the ground overcame the average geothermal heat flux by a factor of at least 4 compared to globally averaged heat flux through continents (and still by a factor of 2.5 compared to the ocean situation). Apparently, this was also valid for the cited estimates from other lakes. We concluded that factors beyond the general temperature gradient from the inner Earth to the surface had to be involved in the heat transport. Differences of deep water temperatures and groundwater temperatures as well as local conditions, such as in volcanic activity and groundwater flow, were responsible for the geothermal heat flux into lakes. 


\section{Acknowledgements}

This work was supported by Japan Society for the Promotion of Science (JSPS). Field work was supported by Dr. Wataru Makino of Tohoku University in Sendai (Lake Towada and Lake Tazawa). We thank the editors Jotaru Urabe and Tomoyasu Fujii as well as the anonymous reviewers for their comments.

\section{References}

Abukawa K., Yamamuro M., Kikvidze Z., Asada A., Xu C., Sugimoto K. (2012): Assessing the biomass and distribution of submerged aquatic vegetation using multibeam echo sounding in Lake Towada, Japan. Limnology, 13, (online first) DOI 10.1007/s10201-0120383-7

Boehrer B. and Schultze M. (2008): Stratification of lakes, Rev. Geophys., 46, RG2005, doi:10.1029/2006RG000210.

Boehrer B., Fukuyama R. and Chikita K. (2008): Stratification in very deep, purely thermally stratified lakes, Geophys. Res. Lett., 35, L16405, doi:10.1029/2008GL034519.

Boehrer B., Fukuyama R., Chikita K., Kikukawa H. (2009): Deep water stratification in Japan's very deep caldera lakes Ikeda, Towada, Tazawa, Kuttara, Toya and Shikotsu, Limnology. 10:17-24. DOI 10.1007/s10201-008-0257-1

Boehrer B. (2012) Double diffusive convection in lakes. 223-224. In: Bengtsson L., Herschy R.W., Fairbridge R.W. (2012) Encyclopedia of lakes and reservoirs, Springer.

Boehrer B., Golmen L,, Løvik J.E., Rahn K., Klaveness D. (2012) Thermobaric stratification in very deep Norwegian freshwater lakes, (under revision)

Böhrer B., Heidenreich H., Schimmele M., Schultze M. (1998): Numerical prognosis for salinity profiles of future lakes in the opencast mine Merseburg-Ost. International Journal of Salt Lake Research 7, 235-260

Chikita K., Sakata K. and Hino S. (1995): Transportation of suspended sediment slowly settling in a caldera lake. Jpn. J. Limnol., 56, 4, 245-257

Crawford G.B. and Collier R.W. (1997): Observations of deep mixing in Crater Lake, Oregon. Limnol. Oceanogr. 42: 299-306.

Crawford G.B. and Collier R.W. (2007): Long- term observations of deepwater renewal in Crater Lake, Oregon. Hydrobiologia, 574: 47-68. doi 10.1007/s10750-006-0345-3.

Hirae,T., K. Sakamoto, T. Sakae and T.Kokuu (1997): Environment and water quality of Lake Ikeda. Ann. Rep. Kagoshima Pref. Inst. Environ. Sci. 13: 55-64 (in Japanese) Imboden D.M. and Wüest A. (1995): Mixing Mechanisms in Lakes. In: Lerman A. Imboden D. and Gat J. (eds.): Physics and Chemistry of Lakes. Springer-Verlag, Berlin, 83-138.

ISO standard 7888 (1985): Water quality: determination of electrical conductivity, International Organization for Standardization, www.iso.org.

Kano K., Ohguchi T., Hayashi S., Yanai K. (2007): Tazawako caldera and its eruption products. Proceedings of the Geological Society of Japan, 114, 70. (in Japanese)

305 Karakas G., Brookland I., Boehrer B. (2003): Physical characteristics of Acidic Mining Lake 111. Aquatic Sciences 65: 297-307.

Kelley, D. E. (1984): Effective Diffusivities Within Oceanic Thermohaline Staircases, J. Geophys. Res., 89, 10484-10488. 
Kudo T. (2010): Considerations on the formation age of Mikadoishi Lava Dome at Towada volcano, Northeast Japan. Bull. Geol. Surv. Japan, vol. 61 (11/12), 477-484. (in Japanese)

Momii K. (2003): Estimation of evaporation from Lake Ikeda, Kagoshima. J. Japan Soc. Hydrol. \& Water Resour. 16: 142-151 (in Japanese)

Nishimura R., Tsunogai U., Ishibashi J., Wakita H., Nojiri Y. (1999): Origin of 13Cenriched methane in the crater lake Towada, Japan. Geochem J 33:277-283

Pollack H.N., Hurter S.J., Johnson J.R., (1993): Heat flow from the Earth's interior: analysis of the global data set. Rev. Geophys. 31, 267-280; DOI 10.1029/93RG01249.

Schmid M., Busbridge M., Wüest A. (2010) Double diffusive convection in Lake Kivu, Limnol. Oceanogr. 55, 225-238. DOI: 10.4319/lo.2010.55.1.0225

Schmid, M., Lorke A., Dinkel Ch., Wüest A., Tanyileke G. (2004): Double-diffusive convection in Lake Nyos, Cameroon. Deep-Sea Res. 51: 1097-1111.

Terada, S. (1996): Study of water temperature in Lakes Ikeda and Unagi. Graduation Thesis of Faculty of Fisheries, Kagoshima Univ. (In Japanese)

von Rohden C. and Ilmberger J. (2001): Tracer experiment with sulphur hexafluoride to quantify the vertical transport in a meromictic pit lake. Aquat. Sci. 63: 417-431.

von Rohden C., Boehrer B., Ilmberger J. (2010): Evidence for double diffusion in temperate meromictic lakes: Hydrology and Earth Systems Sciences 14, 667-674.

Yamagata K. (1993): Tephrochronological Study on the Shikotsu and Kuttara Volcanoes in Southwestern Hokkaido, Japan. Journal of Geography 103(3), 268-285.

Yoshimura S. (1936a): A contribution to the knowledge of deep water temperatures of Japanese lakes. Part 1. Summer temperature. Jap. Jour. Astron. Geophys. 13, 2.

Yoshimura S. (1936b): Deep water temperatures of lakes of Japan in Winter. Sea \& Air, 15, 195-208 (in Japanese). 
Table 1: investigated lakes, morphology and location of measuring points and measured geothermal heat flux.

\begin{tabular}{|l|l|l|l|l|l|l|l|}
\hline Name & $\begin{array}{l}\text { Max depth } \\
z_{m}[\mathrm{~m}]\end{array}$ & $\begin{array}{l}\text { Surf. area } \\
A_{0}\left[\mathrm{~km}^{2}\right]\end{array}$ & $\begin{array}{l}\text { Altitude } \\
{[\mathrm{m} \text { asl }]}\end{array}$ & Region & $\begin{array}{l}\text { North } \\
\mathrm{n}^{\circ} \mathrm{n}^{\prime} \mathrm{n} "\end{array}$ & $\begin{array}{l}\text { East } \\
\mathrm{n}^{\circ} \mathrm{n}^{\prime} \mathrm{n} "\end{array}$ & $\begin{array}{l}\text { Heat flux } \\
{\left[\mathrm{W} / \mathrm{m}^{2}\right]}\end{array}$ \\
\hline Shikotsu & 360 & 78.8 & 248 & Hokkaido & 424613 & 1412119 & 0.29 \\
\hline Kuttara & 148 & 4.72 & 258 & Hokkaido & 422957 & 1411113 & 1.0 \\
\hline Tazawa & 423 & 25.7 & 250 & Tohoku & 394313 & 1403943 & 0.27 \\
\hline Towada & 334 & 59 & 401 & Tohoku & 402651 & 1405326 & 18.6 \\
\hline
\end{tabular}




\section{Figure Captions:}

340 Figure 1: Contour maps of the investigated lakes at the same length scale, including their locations in Japan. Contour intervals (annotations in [m]) vary.

Figure 2: Profiles of temperature and electrical conductance $\left(\kappa_{25}\right)$ from caldera lakes in Japan 345 during 2007. July profiles are drawn as broken lines, while November profiles of the same year are drawn in solid black. Exact dates for the measurements and lake names are marked for each line of panels. Third and fourth column of panels show details of the profiles. 


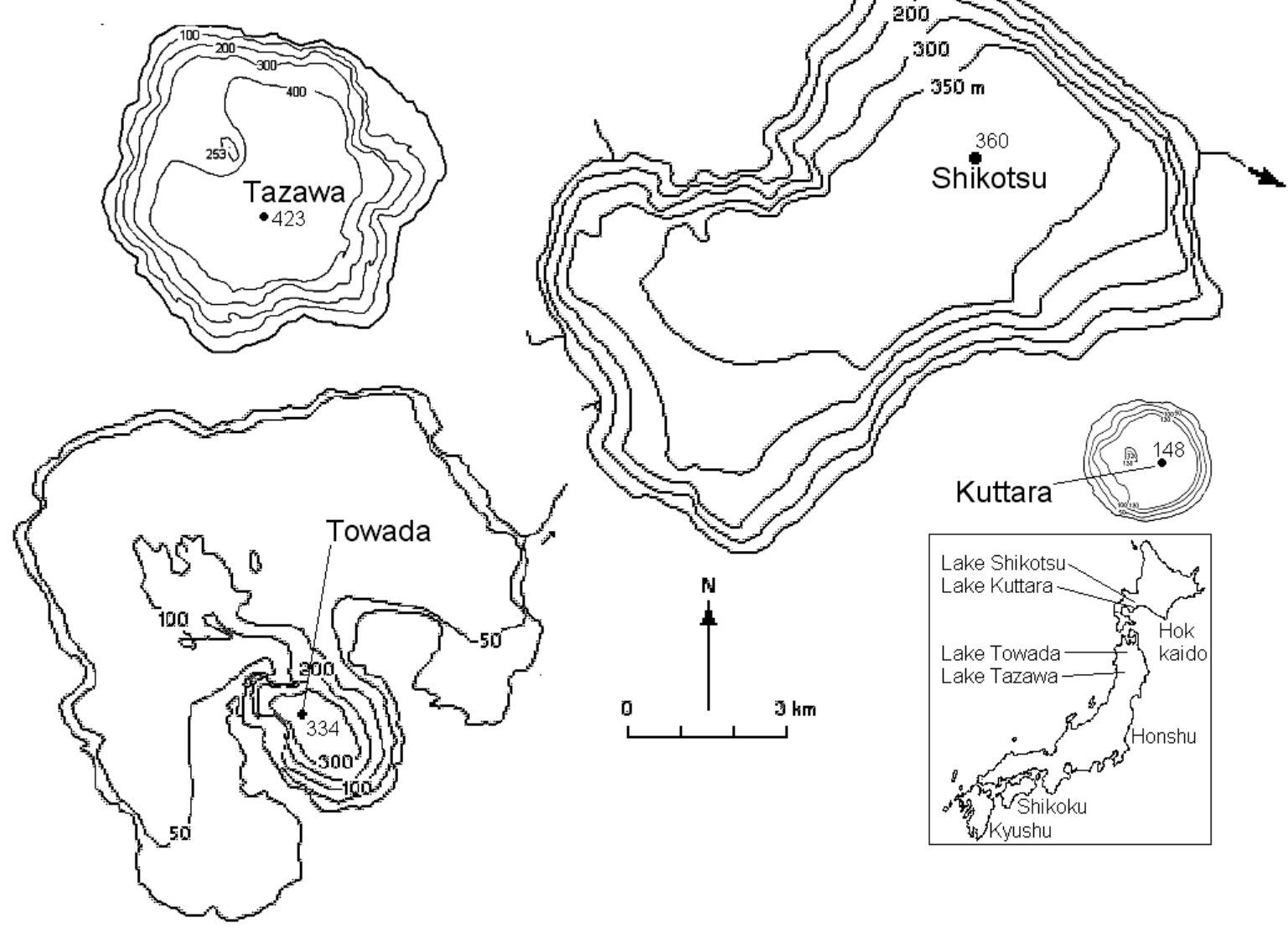

Figure 1: Contour maps of the investigated lakes at the same length scale, including their locations in Japan. Contour intervals (annotations in [m]) vary. 

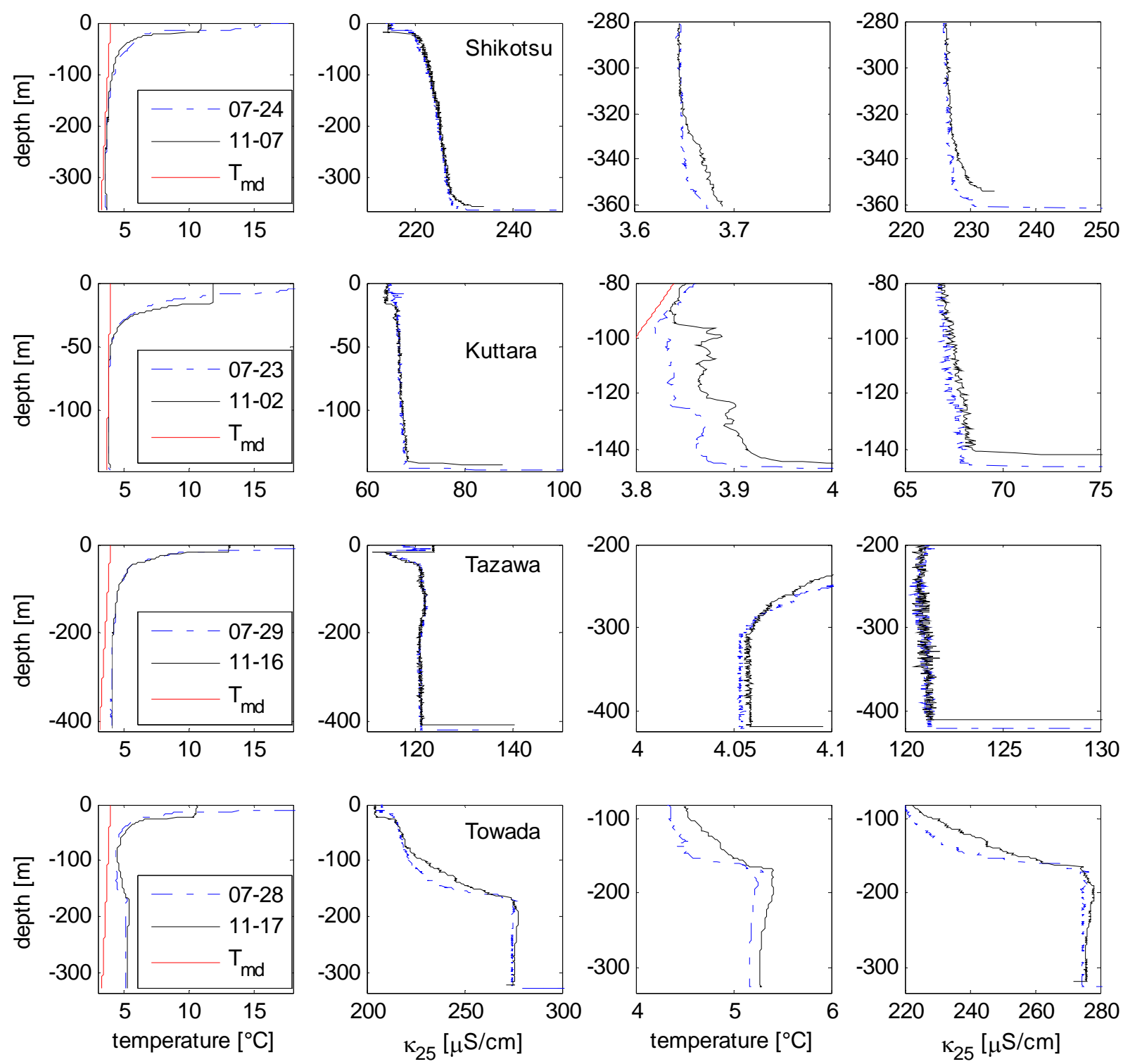

Figure 2: Profiles of temperature and electrical conductance $\left(\kappa_{25}\right)$ from caldera lakes in Japan during 2007. July profiles are drawn as broken lines, while November profiles of the same year are drawn in solid black. Exact dates for the measurements and lake names are marked for each line of panels. Third and fourth column of panels show details of the profiles.

Boehrer et al - suited for FULL WIDTH reproduction. 